\title{
The Imaginary Audience and the Personal Fable: A Test of Elkind's Theory of Adolescent Egocentrism
}

\author{
Evangelia P. Galanaki \\ Department of Special Education and Psychology, Faculty of Primary Education, \\ University of Athens, Athens, Greece \\ Email: egalanaki@primedu.uoa.gr
}

Received February $24^{\text {th }}, 2012$; revised April $2^{\text {nd }}, 2012$; accepted May $5^{\text {th }}, 2012$

\begin{abstract}
The aim of this research was to test empirically Elkind's $(1967,1970,1978)$ Piagetian theoretical formulation for the developmental nature of adolescent egocentrism. The contribution of this study is threefold because it includes: 1) Pubertal development (with a distinction between status and timing), which has been systematically ignored by other investigators; 2) a broad age range (11 - 18 year-old adolescents); and 3) a variety of manifestations and dimensions of egocentrism. The association of the two main forms of adolescent egocentrism - the imaginary audience and the personal fable - with age, gender, pubertal development, and formal operational thought was investigated. Participants were 314 adolescents who completed the Physical Development Scale (Petersen, Crockett, Richards, \& Boxer, 1988), a battery of cognitive tasks (Demetriou, Efklides, \& Platsidou, 1993), the Imaginary Audience Scale (Elkind \& Bowen, 1979), the New Imaginary Audience Scale (Lapsley, Fitzgerald, Rice, \& Jackson, 1989), the Personal Fable Scale (Elkind, personal communication, August 10, 1993), and the New Personal Fable Scale (Lapsley et al., 1989). Findings provided partial support for Elkind's hypothesis. Only the imaginary audience in the form of self-consciousness was associated with grade. Systematic gender differences emerged for several dimensions of imaginary audience and personal fable. For only a few dimensions of imaginary audience and personal fable the expected associations with pubertal and cognitive development, as well as interesting interaction effects, were found. Results are discussed in terms of their implications for Elkind's theory and for alternative interpretations of imaginary audience and personal fable.
\end{abstract}

Keywords: Imaginary Audience; Personal Fable; Pubertal Development; Formal Operational Thought

\section{Introduction}

The concept of egocentrism or centration was introduced and described by Jean Piaget (e.g., 1926, 1929; Piaget \& Inhelder, 1956) as a differentiation failure between the subjective and the objective, a negative by-product of any emergent cognitive system. In the beginning of each cognitive stage, the developing abilities become sources of egocentric errors, as the individual incorporates the world through a process of egocentric assimilation. During adolescence in particular (Inhelder \& Piaget, 1955/1958), formal operational thought enables the adolescent to think about the possible and about his own thought and the thought of others. Using the newly acquired cognitive abilities, and in his or her attempt to adjust the environment to his or her ego, the adolescent fails to distinguish between his or her own theoretical constructions and the point of view of the society which he or she hopes to reform through these constructions.

Following Piaget, David Elkind has elaborated further on adolescent egocentrism and his hypothesis about the developmental nature of egocentrism, a hypothesis that includes both the pubertal and the cognitive changes taking place during adolescence, is as follows (Elkind, 1967):

[The] egocentrism emerges because, while the adolescent can now cognize the thoughts of others, he fails to differentiate between the objects toward which the thoughts of others are directed and those which are the focus of his own concern. Now, it is well known that the young adolescent, because of the phy- siological metamorphosis he is undergoing, is primarily concerned with himself. Accordingly, since he fails to differentiate between what others are thinking about and his own mental preoccupations, he assumes that other people are as obsessed with his behavior and appearance as he is himself. It is this belief that others are preoccupied with his appearance and behavior that constitutes the egocentrism of the adolescent ( $p$. 344).

Elkind described two manifestations of adolescent egocentrism: 1) The imaginary audience, that is, the adolescent's tendency to believe that others are preoccupied with his or her appearance and behavior, that he or she often performs as an actor in front of an audience; and 2) the personal fable, that is, the adolescent's inner belief that he or she is special/unique, omnipotent, invulnerable and therefore he or she can take risks. The imaginary audience and the personal fable account for a large number of typical adolescent behaviors, for example, self-consciousness, daydreaming, shyness, desire for aloneness, tendency to conform to the group norms, exhibitionism, keeping of a diary, risk taking behavior (e.g., Galanaki, 2002), etc. Decentration takes place and egocentrism declines with age, through the biological maturation of cognitive structures and the accumulating social experience.

\section{Empirical Tests of Elkind's Model of Adolescent Egocentrism}

Elkind's interpretation of adolescent egocentrism has been 
partially examined in a series of empirical studies. Quite surprisingly, the association between pubertal development and egocentrism has been investigated in only one study (Cohn et al., 1988). Imaginary audience was higher among those adolescents with more advanced pubertal status, but this weak association disappeared when age was statistically controlled. In a relevant study (Hansell, Mechanic, \& Brondolo, 1986), where tendency for introspection and not egocentrism per se was assessed, a similar finding emerged, although the correlations were rather low: adolescents with more advanced pubertal development were those who were more inclined towards introspection. It seems, then, that physical changes and the accompanying heightened social expectations may lead adolescents to turn their attention to the self.

The expected association between cognitive development and egocentrism has received only partial empirical support. Elkind himself has not assessed formal operational thought in his own research. The expected peak of egocentrism in the first phases of the stage of formal operations and the expected decline when these abilities have been consolidated was found in a few studies (Hudson \& Gray, 1986, only for the imaginary audience; Rycek, Stuhr, McDermott, Benker, \& Swartz, 1998, although the association was weak). In some other studies, no association between formal operations and egocentrism was found (Goossens, 1984, study 3; Jahnke \& Blanchard-Fields, 1993; Kelly, Jones, \& Adams, 2002; O’Connor \& Nikolic, 1990; Peterson, 1982). The unexpected finding that egocentrism is high during the concrete operational stage and declines afterwards emerged from some other studies (Gray \& Hudson, 1984; Pesce \& Harding, 1986; Riley, Adams, \& Nielsen, 1984). And, finally, an unexpected negative correlation between egocentrism and formal operations emerged in another research (Lapsley, Milstead, Quintana, Flannery, \& Buss, 1986, study 1).

Similarly, research data on the association between the imaginary audience/personal fable and age are contradictory. According to Piagetian theory, a decline of egocentrism is expected during the end of adolescence, as a consequence of the consolidation of formal operations in combination with the establishment of interpersonal intimacy. This decline was found in a number of studies (Enright, Lapsley, \& Shukla, 1979; Enright, Shukla, \& Lapsley, 1980; Galanaki, 1996; Goossens, 1984, study 2; Goossens, Seiffge-Krenke, \& Marcoen, 1992, study 2; Lapsley et al., 1986, study 2; Lapsley, Jackson, Rice, \& Shadid, 1988; Lapsley, Fitzgerald, Rice, \& Jackson, 1989; Lechner \& Rosental, 1983; Markstrom \& Mullis, 1986; Vartanian \& Powlishta, 1996). Also, Elkind and Bowen (1979) found the expected curvilinear relationship for the imaginary audience from the fourth to the twelfth grade, with a peak in the eighth grade; the peak in the eighth grade was also found by Alberts, Elkind, and Ginsberg (2007). And Hauck, Martens, and Wetzel (1986) found a peak in the 12 - 14 year-old group in contrast to younger and older adolescents. However, there is also the unexpected increase with age (Adams \& Jones, 1981; Cohn et al., 1988; Goossens et al., 1992, study 1; Rycek et al., 1998), as well as the finding that young adults experience heightened egocentrism (Frankenberger, 2000; Peterson, \& Roscoe, 1991; Schwartz, Maynard, \& Uzelac, 2008). And, finally, no association was found with age in some other investigations (Goossens, 1984, study 1; Gray \& Hudson, 1984; Hudson \& Gray, 1986; Jahnke \& Blanchard-Fields, 1993; Lapsley et al., 1986, study 1; Peterson, 1982; Montgomery, 2005; Richter, Reaves, Deaver,
\& Lacy, 1982).

Furthermore, consistent gender differences in the experience of the imaginary audience and personal fable phenomena are incongruent with a cognitive interpretation of adolescent egocentrism. Females tend to exhibit more imaginary audience ideation than males, as has been shown in a quite large number of investigations (Elkind \& Bowen, 1979; Goossens, 1984, study 2; Goossens et al., 1992, studies 1 and 2; Gray \& Hudson, 1984; Hauck et al., 1986; Hudson \& Gray, 1986; Markstrom \& Mullis, 1986; Montgomery, 2005; Pesce \& Harding, 1986; Richter et al., 1982; Riley et al., 1984; Ryan \& Kuczkowski, 1994; Rycek et al., 1998). Fewer studies have shown that males have higher imaginary audience (Anolik, 1981; Greene, Rubin, Walters, \& Hale, 1996; Lechner \& Rosenthal, 1984) and personal fable scores than females (Goossens, Beyers, Emmen, \& van Aken, 2002; Lapsley et al., 1989). More recently, an attempt to discover whether there are gender differences in the dimensions of the personal fable indicated that girls experience invulnerability and omnipotence more frequently than boys, whereas boys score higher on uniqueness (Aalsma, Lapsley, \& Flannery, 2006); in another investigation (Alberts, Elkind, \& Ginsberg, 2007) boys were found to experience invulnerability more frequently than girls. No gender differences were found in a few other investigations (Adams \& Jones, 1981; Enright et al., 1979; Jahnke \& Blanchard-Fields, 1993; Lapsley et al., 1988; Peterson, 1982; Vartanian \& Powlishta, 1996).

It appears, then, that only contradictory results have been found for the developmental nature of adolescent egocentrism due, partly at least, to the different measures used and to the restricted age ranges in some investigations. Also, quite surprisingly, the original hypothesis formulated by Elkind and including both pubertal and cognitive development has not been tested yet. This gap in the literature has not been pointed out even by critical reviewers of the field (e.g., Vartanian, 2000), although some investigators (Adams \& Jones, 1981; Goossens, 1984; Lapsley, 1993) have proposed that the role of puberty should be a goal for future research. In addition, as is evident in the above literature review, the imaginary audience and the personal fable phenomena are rather neglected research topics in the last decade.

\section{Aims and Hypotheses}

The aim of this research was to test empirically Elkind's (1967, 1970, 1978) Piagetian theoretical formulation for the developmental nature of adolescent egocentrism, that is, the relation of egocentrism to pubertal development and formal operational thought. The contribution of this study is: 1) The inclusion of pubertal development which was ignored by other researchers; 2) the distinction between pubertal level, that is, the adolescent's current level of pubertal development, and pubertal timing, that is, the timing of pubertal onset relative to peers (these two concepts are often confused); 3) the broad age range of the sample (11 - 18 years) — in many studies the sample was seriously restricted as to the age range; and 4) the study of different manifestations and dimensions of egocentrismalso, in all studies only one or two of the existing instruments measuring the manifestations of egocentrism have been used.

Imaginary audience and personal fable are expected to decline with age (Hypothesis 1). Girls are expected to have higher imaginary audience scores than boys, whereas boys are expected to have higher personal fable scores than girls (Hy- 
pothesis 2). This has been found in other studies, although it is not predicted by Elkind's formulation. Adolescents in the first pubertal levels are hypothesized to have higher imaginary audience and personal fable scores than the others, according to Elkind's hypothesis (Hypothesis 3). Early- and late-maturing adolescents are expected to have higher imaginary audience and personal fable scores than the others, because they are "different" from their peers with respect to external appearance, preparation for puberty, subjective feelings about their changes, and significant people's reactions to the changes (the "deviance" hypothesis; Petersen, 1988; Petersen \& Crockett, 1985); for these reasons they are likely to be preoccupied by themselves and place much emphasis on the opinion of others about them (Hypothesis 4). Adolescents in the first formal operational level are expected to have higher imaginary audience and personal fable scores, according to Elkind's hypothesis (Hypothesis 5). Interactions between pubertal development and cognitive development are also expected, as adolescents who are in the first pubertal levels, or are early or late maturers, and, at the same time, are in the first formal operational level, may be more likely to experience the imaginary audience and personal fable ideations than all other subgroups of adolescents (Hypothesis 6).

\section{Method}

\section{Participants}

The sample consisted of 314 adolescents from Athens and semi-rural areas of Greece; 123 of them were boys and 191 were girls. Seventy one of them were from the first grade (mean age: 12.4 years) and 83 from the third grade (mean age: 14.4 years) of the lower secondary school (from now on referred to as seventh graders and ninth graders, respectively); 84 were from the second grade (mean age: 16.4 years) and 76 were from the third grade (mean age: 17.3 years) of the upper secondary school (from now on referred to as eleventh graders and twelfth graders, respectively). From Athens (the capital of Greece) were 159 adolescents $(5.6 \%)$ and from other large cities were $155(49.4 \%)$. Five schools participated in the study. The schools were randomly selected, with the use of random selection process, from the catalogue of schools provided by the Ministry of Education. Participants came mainly from low-tomiddle socioeconomic background. Parental consent was obtained for all of them.

\section{Measures}

1) Physical Development Scale (PDS; Petersen, Crockett, Richards, \& Boxer, 1988). The adolescent assesses his or her own pubertal development, that is, the observable physical changes and secondary sex characteristics, which have psychological significance and have been found to be related to various indices of psychological adjustment more strongly than the non-observable pubertal events. Two variables were distinguished: a) pubertal status and b) pubertal timing. Three levels of pubertal status were distinguished based on the criteria proposed by Tanner (1962): i) first pubertal (early pubertal + midpubertal) $(n=84)$, ii) late pubertal $(n=168)$, and iii) postpubertal $(n=62)$. Early pubertal $(n=16)$ and midpubertal level $(n$ $=68$ ) were collapsed into the first pubertal level, due to the small number of adolescents in the early pubertal level. For pubertal timing, three categories were distinguished on the basis of their deviation (1 $S D)$ from the sample's mean: i) Early maturers $(n=48)$, ii) on-time maturers $(n=220)$, and iii) late maturers $(n=46)$. The internal consistency (Cronbach alpha) of the PDS is satisfactory: .81.

2) Battery of Cognitive Tasks (BCT; Demetriou, Efklides, \& Platsidou, 1993; Demetriou, Platsidou, Efklides, Metallidou, \& Shayer, 1993). The battery assesses propositional reasoning, verbal analogies (i.e., understanding of categorical relations), mathematical analogies (i.e., understanding of second-order relations), and experimental thinking (i.e., combinatorial thinking, hypothesis testing, isolation of variables, recognition of causal relations). Three levels of formal operational thought were distinguished by means of discrimination level analysis (Shayer, Demetriou, \& Pervez, 1988): i) early formal level ( $n=$ $70)$, ii) middle formal level $(n=124)$, and iii) late formal level $(n=120)$. Initially, five levels were distinguished, but the first $(n=8)$ and the fifth $(n=4)$ level were collapsed with the second and the third level, respectively, due to the small number of adolescents in each one of them. The internal consistency (Cronbach alpha) of the BCT is satisfactory: .83.

3) Imaginary Audience Scale (IAS; Elkind \& Bowen, 1979). The scale consists of 12 short vignettes assessing self-consciousness, a consequence of the imaginary audience, and, more specifically, the adolescent's reluctance to reveal aspects of self to others. The scale has two subscales: a) the Abiding Self subscale, which assesses potentially self-revealing situations (e.g., talking about your hobby in front of the class); and b) the Transient Self subscale, which assesses potentially embarrassing situations of a momentary sort (e.g., going to a party with a grease spot on your trousers). The internal consistency (Cronbach alpha) of the IAS is .62 (.53 for the Abiding Self and .52 for the Transient Self subscale).

4) New Imaginary Audience Scale (NIAS; Lapsley et al., 1989). The scale consists of 30 items assessing object relational ideation or interpersonal fantasies, for example, daydreaming about others' reactions to one's accomplishments (e.g., "How often do you imagine yourself rescuing a friend from danger?"). The content of this scale is based on the psychodynamic theories of Blos, Mahler and Josselson. The internal consistency (Cronbach alpha) of the NIAS is satisfactory: .82 .

5) Personal Fable Scale (PFS; Elkind, personal communication, August 10,1993). The scale consists of 18 items assessing three dimensions of personal fable: a) speciality (e.g., believing that one of your teachers thinks of you as special and different from the other kids); b) invulnerability (e.g., believing that you get away with a lot of stuff, other kids get in trouble for); and c) risk taking (e.g., a lot of times not studying for exams because you feel confident you will do well anyway). Both positive and negative sides of each dimension are assessed (i.e., feeling special for positive and negative personality traits and behaviors, feeling vulnerable or invulnerable, and taking risks when estimating that the consequences will be positive or negative). The internal consistency (Cronbach alpha) of the PFS is .52 (.49 for speciality, .44 for invulnerability, and .48 for risk taking). The internal consistency of the PFS is rather unsatisfactory, and this should be taken into account when interpreting the results.

6) New Personal Fable Scale (NPFS; Lapsley et al., 1989). The scale consists of 46 items assessing three dimensions of personal fable: a) uniqueness (e.g., "No one has the same thoughts and feelings I have"); b) omnipotence (e.g., "I believe 


\section{E. P. GALANAKI}

I can do anything I set my mind to"); and c) invulnerability (e.g., "I am not afraid to do dangerous things"). The internal consistency (Cronbach alpha) for the NPFS is satisfactory: .78 (.77 for uniqueness, .69 for omnipotence, and .65 for invulnerability).

\section{Procedure}

Participants completed the measures in group sessions in their classrooms. The measures were administered by three research assistants. To reduce order effects, measures were randomized across portions of the sample; however the Pubertal Development Scale was always administered in the end because of its more "personal" nature than the other instruments. Participants were informed that they were going to participate in a research examining what people of their age think and feel about themselves and others. They were encouraged to write a code name of their choice on the questionnaires they completed. All adolescents agreed to participate in the study. The procedure lasted about 90 minutes, with a break in between.

\section{Results}

A series of multivariate analyses of variance (MANOVA), as well as analyses of variance (ANOVA) only for the imaginary audience as operationalized by Lapsley (i.e., as a unidimensional phenomenon), were done to examine the associations among imaginary audience/personal fable and age, gender, pubertal development and cognitive development. Due to the large number of empty cells, it was not possible to include all four "independent" variables in the same analysis, therefore a series of analyses of variance were done with three of the above factors on all possible combinations. For the sake of brevity, only statistically significant or marginally significant (probability level up to .08) results will be reported.

\section{Imaginary Audience/Personal Fable and Age}

Means and standard deviations of all variables as a function of age (grade) and for the total sample are presented in Table $\mathbf{1 .}$

Only one analysis yielded statistically significant results for age. A Gender $\times$ Grade $\times$ Pubertal Level MANOVA for the Imaginary Audience (Abiding Self and Transient Self) showed a statistically significant multivariate effect of Grade: Pillai's trace $=.09, F(6,586)=4.34, p<.001$. Univariate tests indicated a significant effect of grade only on Abiding Self: $F(3$, $293)=7.86, p<.001$. Post-hoc Scheffé comparisons indicated that eleventh and twelfth graders had significantly higher scores than seventh and ninth graders on self-consciousness as regards abiding personality traits.

\section{Imaginary Audience/Personal Fable and Gender}

Means and standard deviations of all variables as a function of gender are presented in Table 1.

A Gender $\times$ Grade $\times$ Pubertal Level MANOVA for the Imaginary Audience (Abiding Self and Transient Self) showed a statistically significant multivariate effect of Gender, Pillai's trace $=.03, F(2,292)=4.64, p<.001$. Univariate tests indicated a significant effect of gender on Abiding Self, $F(1,293)=$ $6.62, p<.01$; and on Transient Self, $F(1,293)=5.30, p<.05$. Girls had significantly higher scores than boys on self-consciousness as regards their reluctance to reveal abiding personality traits and transient aspects of the self.

Table 1.

Means and standard deviations of all forms and dimensions of egocentrism as a function of gender, grade and for the total sample.

\begin{tabular}{|c|c|c|c|c|c|c|c|c|c|c|c|c|c|c|}
\hline \multirow{3}{*}{ Scales-Variables } & \multicolumn{4}{|c|}{ Gender } & \multicolumn{8}{|c|}{ Grade } & \multirow{2}{*}{\multicolumn{2}{|c|}{$\begin{array}{c}\text { Total } \\
\mathrm{n}=314\end{array}$}} \\
\hline & \multicolumn{2}{|c|}{$\begin{array}{c}\text { Boys } \\
\mathrm{n}=123\end{array}$} & \multicolumn{2}{|c|}{$\begin{array}{c}\text { Girls } \\
\mathrm{n}=191\end{array}$} & \multicolumn{2}{|c|}{$\begin{array}{c}7 \text { th grade } \\
n=71\end{array}$} & \multicolumn{2}{|c|}{$\begin{array}{c}9 \text { th grade } \\
\mathrm{n}=83\end{array}$} & \multicolumn{2}{|c|}{$\begin{array}{c}11 \text { th grade } \\
n=84\end{array}$} & \multicolumn{2}{|c|}{$\begin{array}{c}12 \text { th grade } \\
n=76\end{array}$} & & \\
\hline & $\mathrm{M}$ & SD & $\mathrm{M}$ & SD & $\mathrm{M}$ & SD & $\mathrm{M}$ & $\mathrm{SD}$ & $\mathrm{M}$ & $\mathrm{SD}$ & $\mathrm{M}$ & SD & M & $\mathrm{SD}$ \\
\hline $\begin{array}{l}\text { Imaginary Audience } \\
\text { Scale }\end{array}$ & 1.72 & .32 & 1.83 & .21 & 1.71 & .27 & 1.77 & .31 & 1.82 & .31 & 1.83 & .31 & 1.78 & .31 \\
\hline Abiding Self & 1.69 & .37 & 1.81 & .38 & 1.62 & .32 & 1.71 & .36 & 1.84 & .41 & 1.88 & .37 & 1.77 & .38 \\
\hline Transient Self & 1.74 & .42 & 1.84 & .35 & 1.80 & .38 & 1.83 & .39 & 1.80 & .38 & 1.79 & .37 & 1.80 & .38 \\
\hline $\begin{array}{l}\text { New Imaginary } \\
\text { Audience Scale }\end{array}$ & 2.27 & .35 & 2.20 & .35 & 2.26 & .39 & 2.25 & .34 & 2.15 & .29 & 2.25 & .37 & 2.23 & .35 \\
\hline $\begin{array}{l}\text { Personal Fable } \\
\text { Scale }\end{array}$ & 1.82 & .27 & 1.72 & .23 & 1.76 & .28 & 1.79 & .25 & 1.73 & .23 & 1.77 & .25 & 1.76 & .25 \\
\hline Speciality-Positive & 1.86 & .51 & 1.75 & .48 & 1.71 & .46 & 1.85 & .54 & 1.73 & .50 & 1.88 & .48 & 1.79 & .49 \\
\hline Speciality-Negative & 1.89 & .47 & 1.91 & .48 & 1.91 & .48 & 1.97 & .48 & 1.91 & .48 & 1.81 & .45 & 1.90 & .47 \\
\hline Invulnerability-Pos. & 1.86 & .47 & 1.75 & .46 & 1.85 & .53 & 1.77 & .47 & 1.79 & .43 & 1.78 & .44 & 1.79 & .46 \\
\hline Invulnerability-Neg. & 1.53 & .48 & 1.59 & .45 & 1.54 & .50 & 1.58 & .46 & 1.58 & .44 & 1.55 & .46 & 1.56 & .53 \\
\hline Risk Taking-Pos. & 1.87 & .57 & 1.58 & .47 & 1.63 & .54 & 1.73 & .54 & 1.66 & .49 & 1.76 & .55 & 1.70 & .46 \\
\hline Risk Taking-Neg. & 1.86 & .49 & 1.61 & .49 & 1.77 & .51 & 1.71 & .49 & 1.68 & .52 & 1.68 & .51 & 1.71 & .51 \\
\hline $\begin{array}{l}\text { New Personal Fable } \\
\text { Scale }\end{array}$ & 2.54 & .34 & 2.46 & .36 & 2.47 & .38 & 2.52 & .36 & 2.52 & .34 & 2.45 & .36 & 2.49 & .36 \\
\hline Uniqueness & 2.63 & .59 & 2.71 & .58 & 2.62 & .61 & 2.70 & .58 & 2.70 & .56 & 2.68 & .59 & 2.68 & .58 \\
\hline Omnipotence & 2.68 & .51 & 2.56 & .45 & 2.52 & .50 & 2.61 & .50 & 2.69 & .44 & 2.60 & .46 & 2.61 & .48 \\
\hline Invulnerability & 2.33 & .35 & 2.14 & .41 & 2.28 & .36 & 2.27 & .39 & 2.19 & .45 & 2.11 & .37 & 2.21 & .40 \\
\hline
\end{tabular}

Note: Imaginary audience scale, Personal fable scale: 1 - 3; New imaginary audience scale, New personal fable scale: 1 - 4 . 
A Gender $\times$ Grade $\times$ Pubertal Level ANOVA for the Imaginary Audience as object relational ideation (NIAS) showed a marginally significant effect of gender, $F(1,293)=3.32, p$ $<.07$. Boys had significantly higher scores than girls on the imaginary audience ideation.

A Gender $\times$ Grade $\times$ Pubertal Level MANOVA for the Personal Fable (Speciality-Positive, Speciality-Negative, Invulnerability-Positive, Invulnerability-Negative, Risk Taking-Positive, Risk Taking-Negative) showed a statistically significant multivariate effect of Gender, Pillai's trace $=.06, F(6,288)=2.81, p$ $<.05$. Univariate tests indicated a statistically significant effect of gender on Speciality-Positive, $F(1,293)=4.47, p<.05$; Invulnerability-Positive, $F(1,293)=5.32, p<.05$; Risk TakingPositive, $F(1,293)=6.98, p<.01$; and Risk Taking-Negative, $F(1,293)=7.12, p<.01$. Boys had significantly higher scores than girls on all the above dimensions of the personal fable.

A Gender $\times$ Grade $\times$ Pubertal Level MANOVA for the Personal Fable (Uniqueness, Omnipotence, Invulnerability) showed a statistically significant multivariate effect of Gender, Pillai's trace $=.08, F(3,291)=8.22, p<.01$. Univariate tests indicated a statistically significant effect of gender on Omnipotence, $F(1$, $293)=5.35, p<.05$; and Invulnerability, $F(1,293)=16.90, p$ $<.01$. Boys had significantly higher scores than girls on these two dimensions of the personal fable.

\section{Imaginary Audience/Personal Fable and Pubertal Level}

Means and standard deviations of all variables as a function of pubertal level are presented in Table 2.

Only one analysis yielded statistically significant results for pubertal level. A Gender $\times$ Grade $\times$ Pubertal Level MANOVA for the Personal Fable (Speciality-Positive, Speciality-Negative,
Invulnerability-Positive, Invulnerability-Negative, Risk TakingPositive, Risk Taking-Negative) showed no statistically significant multivariate effect of Pubertal Level, Pillai's $=.06, F(12$, $578)=1.51$, ns. However, univariate tests indicated a statistically significant effect of Pubertal Level on Risk Taking-Negative, $F(2,293)=3.13, p<.05$. Post-hoc Scheffé comparisons indicated that adolescents in the first pubertal and late pubertal level had significantly higher scores than those in the postpubertal level on the tendency towards risk behaviours even when the consequences are anticipated to be negative.

\section{Imaginary Audience/Personal Fable and Pubertal Timing}

Means and standard deviations of all the variables as a function of pubertal timing are presented in Table 2 .

A Gender $\times$ Grade $\times$ Pubertal Timing MANOVA for the Imaginary Audience (Abiding Self and Transient Self) showed a marginally significant multivariate Gender $\times$ Pubertal Timing interaction: Pillai's $=.03, F(4,580)=2.30, p<.06$. Univariate tests indicated a marginally significant interaction effect on Abiding Self, $F(2,290)=2.58, p<.08$; and Transient Self, $F(2$, $290)=2.99, p<.05$. Figures 1 and 2 show that late maturers have lower scores on these two dimensions of the imaginary audience, respectively, than on-time and early maturers, but this holds only for boys, whereas there seems to be no such differrence among girls.

A Gender $\times$ Grade $\times$ Pubertal Timing ANOVA for the Imaginary Audience as object relational ideation (NIAS) showed a statistically significant Grade $\times$ Pubertal Timing interaction, $F(6,290)=2.87, p<.05$. As shown in Figure 3, only for twelfth graders late maturation is linked with higher levels of imaginary audience ideation than on-time and early maturation.

Table 2.

Means and standard deviations of all forms and dimensions of egocentrism as a function of pubertal status (level and timing).

\begin{tabular}{|c|c|c|c|c|c|c|c|c|c|c|c|c|}
\hline \multirow{3}{*}{ Scales-Variables } & \multicolumn{6}{|c|}{ Pubertal Level } & \multicolumn{6}{|c|}{ Pubertal Timing } \\
\hline & \multicolumn{2}{|c|}{$\begin{array}{l}\text { First Pubertal } \\
\quad \mathrm{n}=84\end{array}$} & \multicolumn{2}{|c|}{$\begin{array}{l}\text { Late Pubertal } \\
\mathrm{n}=168\end{array}$} & \multicolumn{2}{|c|}{$\begin{array}{l}\text { Post Pubertal } \\
n=62\end{array}$} & \multicolumn{2}{|c|}{$\begin{array}{l}\text { Early Maturation } \\
n=48\end{array}$} & \multicolumn{2}{|c|}{$\begin{array}{c}\text { On-Time Maturation } \\
\mathrm{n}=220\end{array}$} & \multicolumn{2}{|c|}{$\begin{array}{l}\text { Late Maturation } \\
n=46\end{array}$} \\
\hline & M & SD & M & SD & M & SD & M & SD & $\mathrm{M}$ & SD & $\mathrm{M}$ & $\mathrm{SD}$ \\
\hline Imaginary Audience Scale & 1.74 & .29 & 1.77 & .30 & 1.88 & .33 & 1.87 & .29 & 1.78 & .30 & 1.74 & .34 \\
\hline Abiding Self & 1.68 & .33 & 1.76 & .37 & 1.89 & .42 & 1.81 & .32 & 1.76 & .38 & 1.76 & .44 \\
\hline Transient Self & 1.80 & .42 & 1.78 & .36 & 1.87 & .38 & 1.92 & .42 & 1.79 & .37 & 1.72 & .39 \\
\hline New Imaginary Audience Scale & 2.26 & .39 & 2.21 & .33 & 2.24 & .35 & 2.15 & .37 & 2.23 & .35 & 2.30 & .33 \\
\hline Personal Fable Scale & 1.76 & .28 & 1.79 & .25 & 1.69 & .20 & 1.75 & .26 & 1.77 & .25 & 1.72 & .25 \\
\hline Speciality-Positive & 1.73 & .47 & 1.84 & .50 & 1.77 & .51 & 1.76 & .48 & 1.80 & .49 & 1.80 & .52 \\
\hline Speciality-Negative & 1.90 & .45 & 1.92 & .48 & 1.84 & .47 & 1.87 & .46 & 1.92 & .47 & 1.83 & .49 \\
\hline Invulnerability-Pos. & 1.81 & .50 & 1.81 & .47 & 1.74 & .39 & 1.70 & .46 & 1.82 & .46 & 1.75 & .47 \\
\hline Invulnerability-Neg. & 1.53 & .51 & 1.60 & .45 & 1.53 & .42 & 1.62 & .50 & 1.56 & .46 & 1.53 & .46 \\
\hline Risk Taking-Pos. & 1.69 & .58 & 1.74 & .52 & 1.60 & .48 & 1.76 & .50 & 1.71 & .52 & 1.57 & .51 \\
\hline Risk Taking-Neg. & 1.76 & .49 & 1.74 & .51 & 1.56 & .48 & 1.65 & .48 & 1.72 & .51 & 1.75 & .54 \\
\hline New Personal Fable Scale & 2.46 & .34 & 2.52 & .36 & 2.45 & .38 & 2.46 & .33 & 2.51 & .34 & 2.45 & .44 \\
\hline Uniqueness & 2.57 & .60 & 2.73 & .57 & 2.69 & .58 & 2.66 & .65 & 2.71 & .57 & 2.56 & .58 \\
\hline Omnipotence & 2.57 & .50 & 2.63 & .47 & 2.60 & .48 & 2.62 & .48 & 2.61 & .46 & 2.56 & .57 \\
\hline Invulnerability & 2.28 & .33 & 2.22 & .43 & 2.10 & .39 & 2.14 & .40 & 2.22 & .39 & 2.24 & .46 \\
\hline
\end{tabular}

Note: Imaginary audience scale, Personal fable scale: 1 - 3; New imaginary audience scale, New personal fable scale: 1 - 4. 


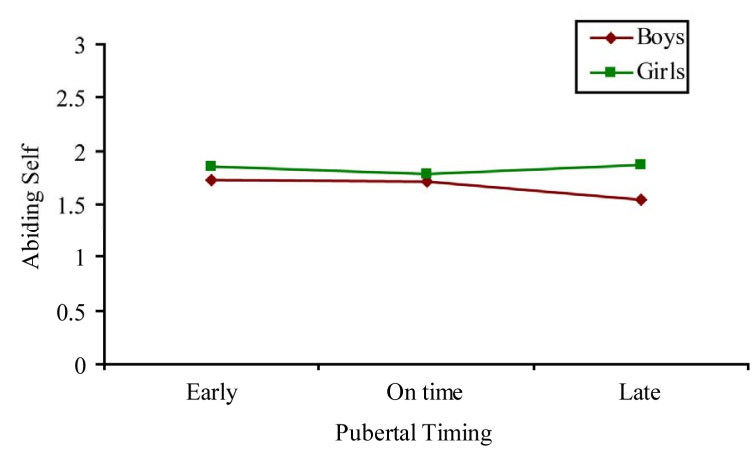

Figure 1.

Means of abiding self subscale as a function of gender and pubertal timing.

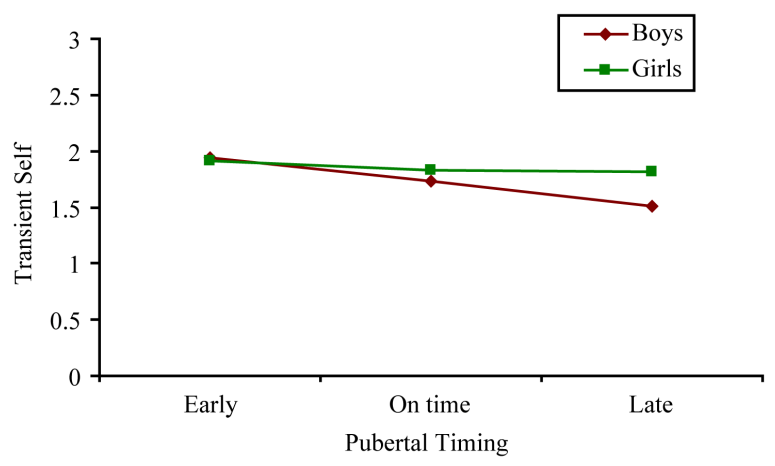

Figure 2.

Means of transient self subscale as a function of gender and pubertal timing.

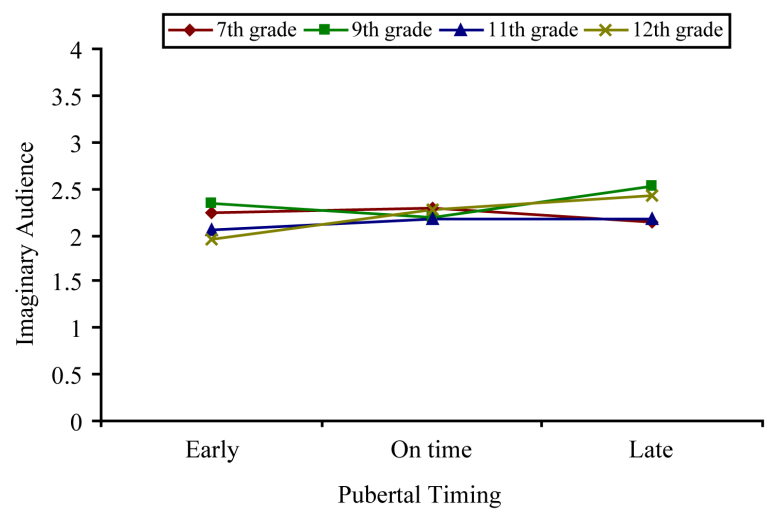

Figure 3.

Means of imaginary audience as a function of grade and pubertal timing.

A Gender $\times$ Grade $\times$ Pubertal Timing MANOVA for the Personal Fable (Speciality-Positive, Speciality-Negative, Invulnerability-Positive, Invulnerability-Negative, Risk Taking-Positive, Risk Taking-Negative) showed a marginally significant multivariate Gender $\times$ Pubertal Timing interaction: Pillai's $=.07, F(12,572)=1.65, p<.07$. Univariate tests indicated a statistically significant interaction effect only on SpecialityPositive: $F(2,290)=4.21, p<.05$. Figure 4 shows that, whereas among girls there are no mean differences for pubertal timing, among boys late maturers have higher speciality scores than on-time and early maturers.

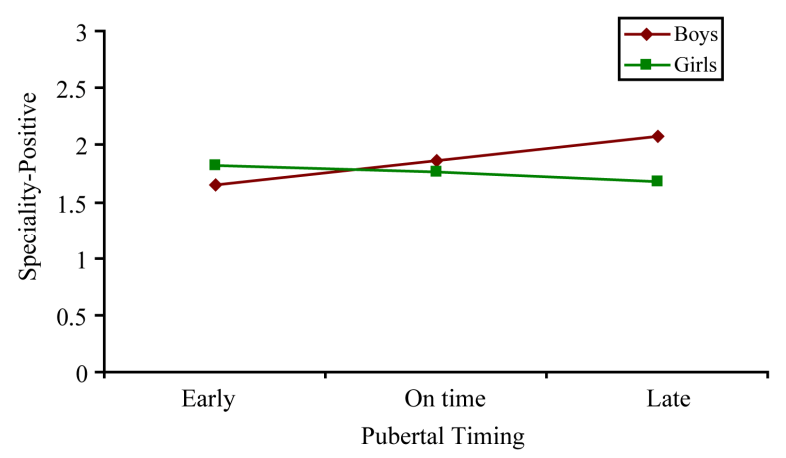

Figure 4.

Means of speciality-positive as a function of gender and pubertal timing.

A Gender $\times$ Grade $\times$ Pubertal Timing MANOVA for the Personal Fable (Uniqueness, Omnipotence, Invulnerability) showed no statistically significant multivariate Gender $\times \mathrm{Pu}$ bertal Timing interaction: Pillai's $=.03, F(6,578)=1.48$, ns. However, univariate tests indicated a marginally significant interaction effect on Omnipotence: $F(2,290)=2.89, p<.06$. Figure 5 shows that, whereas among boys late maturers have higher scores on omnipotence than early and on-time maturers, among girls late maturers have lower scores on this dimension of the personal fable than early and on-time maturers.

\section{Imaginary Audience/Personal Fable and Formal Operational Level}

Means and standard deviations of all variables as a function of formal operational level are presented in Table 3.

A Gender $\times$ Grade $\times$ Formal Operational Level MANOVA for the Imaginary Audience (Abiding Self and Transient Self) showed a marginally significant multivariate effect of Formal Operational Level: Pillai's $=.03, F(4,582)=2.18, p<.07$. Univariate tests indicated a statistically significant main effect only on Transient Self, $F(2,291)=4.38, p<.05$. Post-hoc Scheffé comparisons indicated that adolescents in the middle formal level had significantly higher scores than those in the early formal and late formal level on self-consciousness as regards transient aspects of the self.

A Gender $\times$ Grade $\times$ Formal Operational Level ANOVA for the Imaginary Audience as object relational ideation (NIAS) showed a marginally significant effect of Formal Operational Level, $F(1,291)=2.47, p<.08$. Post-hoc Scheffé comparisons indicated that adolescents in the early formal level had significantly higher scores than those in the middle formal level on object relational ideation.

\section{Discussion}

The contribution of this study was to test Elkind's (1967, 1970, 1978) model of adolescent egocentrism, by assessing both the role of pubertal development (level and timing), which has been systematically neglected by other researchers, and formal operational thought.

The expected age trends for imaginary audience and personal fable (Hypothesis 1) were not found. Self-consciousness as regards the adolescent's reluctance to reveal more permanent aspects of the self appeared to increase with age - and this is an unexpected finding, although it is found in some other studies 
Table 3.

Means and standard deviations of all forms and dimensions of egocentrism as a function of formal operational level.

\begin{tabular}{|c|c|c|c|c|c|c|}
\hline \multirow{3}{*}{ Scales-Variables } & \multicolumn{6}{|c|}{ Formal Operational Level } \\
\hline & \multicolumn{2}{|c|}{$\begin{array}{l}\text { Early Formal } \\
\quad \mathrm{n}=70\end{array}$} & \multicolumn{2}{|c|}{$\begin{array}{c}\text { Middle Formal } \\
\mathrm{n}=124\end{array}$} & \multicolumn{2}{|c|}{$\begin{array}{l}\text { Late Formal } \\
\quad \mathrm{n}=120\end{array}$} \\
\hline & M & SD & M & SD & M & $\mathrm{SD}$ \\
\hline Imaginary Audience Scale & 1.74 & .28 & 1.83 & .28 & 1.76 & .33 \\
\hline Abiding Self & 1.68 & .37 & 1.78 & .36 & 1.80 & .40 \\
\hline Transient Self & 1.81 & .38 & 1.88 & .35 & 1.72 & .40 \\
\hline New Imaginary Audience Scale & 2.32 & .38 & 2.19 & .32 & 2.21 & .35 \\
\hline Personal Fable Scale & 1.76 & .24 & 1.76 & .25 & 1.77 & .25 \\
\hline Speciality-Positive & 1.78 & .43 & 1.75 & .51 & 1.85 & .50 \\
\hline Speciality-Negative & 1.91 & .48 & 1.93 & .48 & 1.86 & .46 \\
\hline Invulnerability-Positive & 1.85 & .50 & 1.75 & .45 & 1.81 & .46 \\
\hline Invulnerability-Negative & 1.54 & .48 & 1.64 & .49 & 1.50 & .42 \\
\hline Risk Taking-Positive & 1.70 & .52 & 1.63 & .50 & 1.77 & .56 \\
\hline Risk Taking-Negative & 1.72 & .50 & 1.73 & .52 & 1.69 & .50 \\
\hline New Personal Fable Scale & 2.54 & .35 & 2.44 & .39 & 2.51 & .32 \\
\hline Uniqueness & 2.74 & .58 & 2.62 & .60 & 2.70 & .60 \\
\hline Omnipotence & 2.61 & .48 & 2.56 & .49 & 2.65 & .46 \\
\hline Invulnerability & 2.29 & .33 & 2.18 & .43 & 2.20 & .40 \\
\hline
\end{tabular}

Note: Imaginary audience scale, Personal fable scale: 1 - 3; New imaginary audience scale, New personal fable scale: 1 - 4 .

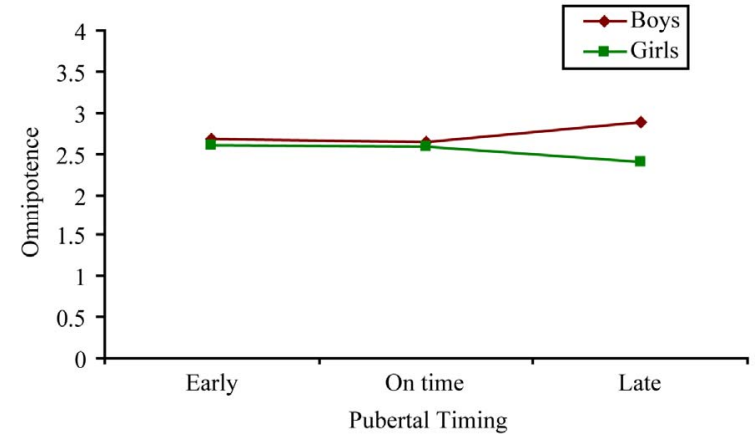

Figure 5.

Means of omnipotence as a function of gender and pubertal timing.

(Adams \& Jones, 1981; Cohn et al., 1988; Goossens et al., 1992, study 1; Peterson, \& Roscoe, 1991; Rycek et al., 1998). It seems that there is a heightened preoccupation with the self at the end of the adolescent period and the beginning of adulthood, a quite normative reaction of the adolescent in front of the developmental tasks of identity formation and individuation.

The absence of any systematic age trend for all other manifestations and dimensions of egocentrism is a disturbing result, but similar to other research findings (Goossens, 1984, study 1; Gray \& Hudson, 1984; Hudson \& Gray, 1986; Jahnke \& Blanchard-Fields, 1993; Lapsley et al., 1986, study 1; Peterson, 1982; Richter et al., 1982). This finding and the fact that selfconsciousness increases with age support the view that the imaginary audience at least may fluctuate during adolescence as a function of the individual's attempt to cope with developmental transitions and life events (Aalsma et al., 2006; Bjorklund \& Green, 1992; Lapsley \& Aalsma, 2006). These fluctuations are not accounted for by Elkind's $(1967,1970,1978)$ model.
Systematic gender differences emerged from the data of this study, confirming in general Hypothesis 2. Self-consciousness is higher among girls, and this is consistent with findings from several other investigations (Elkind \& Bowen, 1979; Goossens, 1984, study 2; Goossens et al., 1992, studies 1 and 2; Gray \& Hudson, 1984; Hauck et al., 1986; Hudson \& Gray, 1986; Markstrom \& Mullis, 1986; Montgomery, 2005; Pesce \& Harding, 1986; Richter et al., 1982; Riley et al., 1984; Ryan \& Kuczkowski, 1994; Rycek et al., 1998). Object relational ideation and various dimensions of the personal fable (i.e., speciality, invulnerability, omnipotence, and risk taking) are higher among boys, independent of age (similar findings by Anolik, 1981; Goossens et al., 2002; Greene et al., 1996; Lapsley et al., 1989; Lechner \& Rosenthal, 1984). These findings may be attributed to the differential socialization of boys and girls, which is still common in the Greek society. Girls are usually brought up to place much emphasis on interpersonal relationships, on feelings about relationships and about self in relationships, therefore they have higher self-consciousness scores than boys. On the other hand, boys are expected to value strength, physical power, athletic abilities, risk taking and leadership in the peer group. Therefore, they have higher personal fable scores and marginally higher imaginary audience scores than girls - when the imaginary audience is in the form of object relational fantasies that include the above domains of life.

Elkind $(1967,1970,1978)$ hypothesized a peak of egocentrism in the beginning of the adolescent's "physiological metamorphosis" (Hypothesis 3). This peak was found, but only for one dimension of the personal fable, that is, risk taking with negative anticipated consequences. This finding is contrary to existing research data (Cohn et al., 1988; Hansell et al., 1986) indicating a peak of the imaginary audience, personal fable, and introspection in the more advanced pubertal levels, although 
this peak may simply reflect an age effect.

Pubertal timing, though, is a stronger correlate of the imaginary audience and the personal fable experience than the level of pubertal development per se. Surprisingly, there is no other research examining this association. The hypothesis that imaginary audience and personal fable are higher among adolescents who deviate from their age mates as to their pubertal development (Hypothesis 4) is partially confirmed. Early pubertal maturation was associated with increased self-consciousness both for permanent and for transient aspects of the self, but only among boys. Self-consciousness was higher among girls and was found to increase with age, perhaps showing a more mature response to the challenges of adolescence. Thus, the finding that early-maturing boys are those who experience the most heightened self-consciousness may simply reflect that these boys are, in general, more mature than their age mates whose pubertal development remains behind. This explanation is further supported by the frequent finding of other investigations that early maturation is an advantage for boys (and not for girls) (Silbereisen \& Kracke, 1993; Simmons \& Blyth, 1987; for a recent review see Susman \& Dorn, 2009).

Imaginary audience, in the form of interpersonal fantasies, is more common among late-maturing adolescents, but this holds only for late adolescence (twelfth grade). It is reasonable to hypothesize that older adolescents feel more vulnerable than younger ones when they face late maturation, and develop compensatory mechanisms, such as fantasies of admiration and acceptance, with which they attempt to cope with this deviance from the age norm.

Furthermore, late maturation is associated with facets of the personal fable, such as, among boys, speciality for positive characteristics and omnipotence. In contrast, late maturation among girls is associated with less intense omnipotence than early and on-time maturation. The fact that late pubertal maturation is a more negative situation for boys than for girls has long ago been documented by several research studies in Europe and the USA (e.g., Alsaker, 1992; Brooks-Gunn, 1988; Simmons \& Blyth, 1987; for reviews see Brooks-Gunn \& Reiter, 1990 and Susman \& Dorn, 2009). The link between deviant pubertal timing and egocentrism among boys holds only for personal fable, as this form of egocentrism is more frequent among boys than girls. However, we should take into account that the above interactions between gender and pubertal timing are marginally significant.

This study failed to find the expected links of egocentrism with formal operations (Hypothesis 5), yet some expected links were found and were all independent of age. Only self-consciousness as a reluctance to reveal transient aspects of the self in front of an audience seemed to be higher among adolescents functioning at the middle formal operational level than at the early formal and late formal level. This curvilinear pattern is consistent with Elkind's hypothesis: formal operations have emerged, but they are not yet consolidated, therefore they become sources of egocentric errors. The imaginary audience in the form of interpersonal fantasies is somewhat heightened among adolescents in the early formal level. This finding can also be accounted for by Elkind's theory, as the onset of formal operations may also play an important role in the emergence of egocentrism. However, one must take into account that in this level were classified adolescents who were likely to operate still in the concrete level, at least on some occasions. Concrete thought has been regarded as adequate for the adolescent's psychosocial adjustment (Bart, 1983; Blasi \& Hoeffel, 1974) and, besides, not all adolescents reach the level of formal operational thought. We should also remember that this finding is marginally significant.

The hypothesized interaction between pubertal development and cognitive development (Hypothesis 6) was not supported by the data of this study. The observed links of these two variables with imaginary audience and personal fable appear to be independent of one another, and this finding is contrary to Elkind's $(1967,1970,1978)$ hypothesis about the joint role puberty and thought play in the emergence of egocentrism.

In this study, which was conducted in the Greek culture, Elkind's hypothesis received partial support. The expected connection between adolescent egocentrism on the one hand and pubertal and cognitive development on the other was found, but only for some forms and dimensions of egocentrism. Elkind's theory cannot explain the fact that nearly all the egocentrism dimensions are differentially associated with age, gender, pubertal development and formal operational thought. This implies that adolescent egocentrism is a multifaceted-multidimensional construct, and that its dimensions need further conceptual clarification. Also, Elkind's theory cannot account for the increase of the imaginary audience in the form of self-consciousness during late adolescence, and for the systematic gender differences in imaginary audience and personal fable.

Results imply the necessity of a broader model for the explanation of adolescent egocentrism than that of Elkind, one that possibly includes psychodynamic changes and social factors. If we assume, for example, that late-maturing boys who have high omnipotence scores seem to use some kind of compensatory or defensive mechanism (Hill \& Lapsley, 2011), and that differential socialization seems to be responsible for the gender differences, which are not predicted by Elkind's hypothesis, we understand why it is important to include other factors in the explanatory model of imaginary audience and personal fable. Therefore, the findings of this study justify the search for an alternative model, such as the "New Look" model described by Lapsley and his associates (Lapsley, 1993; Lapsley \& Rice, 1988), a model that includes such factors (and received support in a recent study among Greek adolescents; Galanaki \& Christopoulos, 2011). At the same time though, we should not ignore the findings of investigations such as this one, which provide some support for the contribution of pubertal and cognitive factors in the emergence of the imaginary audience and personal fable experience, and thus point the necessity of including these factors in a future integrative model.

\section{Acknowledgements}

The author would like to thank N. Lianou, E. Papageorgiou, and G. Papagiannopoulos for their assistance in data collection and coding.

\section{REFERENCES}

Aalsma, M. C., Lapsley, D. K., \& Flannery, D. J. (2006). Personal fables, narcissism, and adolescent adjustment. Psychology in the Schools, 43, 481-491. doi:10.1002/pits.20162

Adams, G. R., \& Jones, R. M. (1981). Imaginary audience behavior: A validation study. Journal of Early Adolescence, 1, 1-10. doi: $10.1177 / 027243168100100102$

Alberts, A., Elkind, D., \& Ginsberg, S. (2007). The personal fable and risk-taking in early adolescence. Journal of Youth and Adolescence, 
36, 71-76. doi:10.1007/s10964-006-9144-4

Alsaker, F. D. (1992). Pubertal timing, overweight, and psychological adjustment. Journal of Early Adolescence, 12, 396-419. doi:10.1177/0272431692012004004

Anolik, S. A. (1981). Imaginary audience behavior, and perceptions of parents among delinquent and non-delinquent adolescents. Journal of Youth and Adolescence, 10, 443-454. doi:10.1007/BF02087938

Bart, W. M. (1983). Adolescent thinking and the quality of life. Adolescence, $18,875-888$.

Bjorklund, D. F., \& Green, B. L. (1992). The adaptive nature of cognitive immaturity. American Psychologist, 47, 46-54. doi:10.1037/0003-066X.47.1.46

Blasi, A., \& Hoeffel, E. C. (1974). Adolescence and formal operations. Human Development, 17, 344-363. doi:10.1159/000271357

Brooks-Gunn, J. (1988). Antecedents and consequences of variation in girls' maturational timing. Journal of Adolescent Health Care, 9, 365-373. doi:10.1016/0197-0070(88)90030-7

Brooks-Gunn, J., \& Reiter, E. O. (1990). The role of pubertal processes. In S. S. Feldman, \& G. R. Elliott (Eds.), At the threshold: The developing adolescent (pp. 16-53). Harvard: Harvard University Press.

Cohn, L. D., Millstein, S. G., Irwin, C. E., Jr., Adler, N. E., Kegeles, S. M., Dolcini, P., \& Stone, G. (1988). A comparison of two measures of egocentrism. Journal of Personality Assessment, 52, 212-222. doi:10.1207/s15327752jpa5202 3

Demetriou, A., Efklides, A., \& Platsidou, M. (1993). The architecture and dynamics of developing mind. Monographs of the Society for Research in Child Development, 58.

Demetriou, A., Platsidou, M., Efklides, A., Metallidou, Y., \& Shayer, M. (1993). The development of quantitative-relational abilities from childhood to adolescence: Structure, scaling, and individual differences. Learning and Instruction, 1, 19-43.

doi:10.1016/0959-4752(91)90017-3

Elkind, D. (1967). Egocentrism in adolescence. Child Development, 38, 1025-1034. doi: $10.2307 / 1127100$

Elkind, D. (1970). Children and adolescents. Interpretive essays on Jean Piaget (3rd ed.). New York: Oxford Universities Press.

Elkind, D. (1978). The child's reality: Three developmental themes. Hillsdale, NJ: Erlbaum.

Elkind, D., \& Bowen, R. (1979). Imaginary audience behavior in children and adolescents. Developmental Psychology, 15, 38-44. doi:10.1037/0012-1649.15.1.38

Enright, R. D., Lapsley, D. K., \& Shukla, D. G. (1979). Adolescent egocentrism in early and late adolescence. Adolescence, 14, 687-695.

Enright, R. D., Shukla, D. G., \& Lapsley, D. K. (1980). Adolescent egocentrism-sociocentrism and self-consciousness. Journal of Youth and Adolescence, 9, 101-116. doi:10.1007/BF02087929

Frankenberger, K. D. (2000). Adolescent egocentrism: A comparison among adolescents and adults. Journal of Adolescence, 23, 343-354. doi:10.1006/jado.2000.0319

Galanaki, E. P. (1996). The imaginary audience and the personal fable: A pilot study of the two manifestations of adolescent egocentrism. Psychology: The Journal of the Hellenic Psychological Society, 3, 119.

Galanaki, E. P. (2001). The imaginary audience and the personal fable in relation to risk behavior and risk perception during adolescence. Psychology: The Journal of the Hellenic Psychological Society, 8, 411-443.

Galanaki, E. P., \& Christopoulos, A. (2011). The imaginary audience and the personal fable in relation to the separation-individuation process during adolescence. Psychology: The Journal of the Hellenic Psychological Society, 18, 85-103.

Goossens, L. (1984). Imaginary audience behavior as a function of age, sex, and formal operational thinking. International Journal of Behavioral Development, 7, 77-93.

Goossens, L., Beyers, W., Emmen, M., \& Van Aken, M. A. G. (2002). The imaginary audience and personal fable: Analyses and concurrent validity of the "New Look" measures. Journal of Research on Adolescence, 12, 193-215. doi:10.1111/1532-7795.00031

Goossens, L., Seiffge-Krenke, I., \& Marcoen, A. (1992). The many faces of adolescent egocentrism: Two European replications. Journal of Adolescent Research, 7, 43-58. doi:10.1177/074355489271004

Gray, W. M., \& Hudson, L. M. (1984). Formal operations and the imaginary audience. Developmental Psychology, 20, 619-627. doi:10.1037/0012-1649.20.4.619

Green, K., Rubin, D. L., Hale, J. L., \& Walters, L. H. (1996). The utility of understanding adolescent egocentrism in designing health promotion messages. Health Communication, 8, 131-152. doi: $10.1207 / \mathrm{s} 15327027 \mathrm{hc} 0802 \_2$

Hansell, S., Mechanic, D., \& Brondolo, E. (1986). Introspectiveness and adolescent development. Journal of Youth and Adolescence, 15, 115-132. doi:10.1007/BF02141733

Hauck, W. E., Martens, M., \& Wetzel, M. (1986). Shyness, group dependence and self-concept: Attributes of the imaginary audience. Adolescence, 21, 529-534.

Hill, P. L., \& Lapsley, D. K. (2011). Adaptive and maladaptive narcissism in adolescent development. In C. T. Barry, P. Kerig, K. Stellwagen, \& T. D. Barry (Eds.), Implications of narcissism and Machiavellianism for the development of prosocial and antisocial behavior in youth (pp. 89-105). Washington, DC: American Psychological Association. doi:10.1037/12352-005

Hudson, L. M., \& Gray, W. M. (1986). Formal operations, the imaginary audience and the personal fable. Adolescence, 21, 751-765.

Inhelder, B., \& Piaget, J. (1958). The growth of logical thinking from childhood to adolescence: An essay on the construction of formal operational structures. New York: Basic Books. doi: 10.1037/10034-000

Jahnke, H. C., \& Blanchard-Fields, F. (1993). A test of two models of adolescent egocentrism. Journal of Youth and Adolescence, 22, 313-326. doi:10.1007/BF01537795

Kelly, K. M., Jones, W. H., \& Adams, J. M. (2002). Using the Imaginary Audience Scale as a measure of social anxiety in young adults. Educational and Psychological Measurement, 62, 896-914. doi:10.1177/001316402236884

Lapsley, D. K. (1993). Toward an integrated theory of adolescent ego development: The "new look" at adolescent egocentrism. American Journal of Orthopsychiatry, 63, 562-571. doi:10.1037/h0079470

Lapsley, D. K., \& Aalsma, M. C. (2006). An empirical typology of narcissism and mental health in late adolescence. Journal of Adolescence, 29, 53-71. doi:10.1016/j.adolescence.2005.01.008

Lapsley, D. K., Fitzgerald, D. P., Rice, K. G., \& Jackson, S. (1989). Separation-individuation and the "new look" at the imaginary audience and personal fable: A test of an integrative model. Journal of Adolescent Research, 4, 483-505. doi: $10.1177 / 074355488944006$

Lapsley, D. K., Jackson, S., Rice, K., \& Shadid, G. E. (1988). Selfmonitoring and the "New Look" at the imaginary audience and the personal fable: An ego-developmental analysis. Journal of Adolescent Research, 3, 17-31. doi:10.1177/074355488831003

Lapsley, D. K., Milstead, M., Quintana, S. M., Flannery, D., \& Buss, R. R. (1986). Adolescent egocentrism and formal operations: Tests of a theoretical assumption. Developmental Psychology, 22, 800-807. doi: 10.1037/0012-1649.22.6.800

Lapsley, D. K., \& Rice, K. G. (1988). The "new look" at the imaginary audience and personal fable: Toward a general developmental model of adolescent ego development. In D. K. Lapsley, \& F. C. Power (Eds.), Self, ego, and identity: Integrative approaches (pp. 109-129). New York: Springer. doi:10.1007/978-1-4615-7834-5_6

Lechner, C. R., \& Rosenthal, D. A. (1984). Adolescent self-consciousness and the imaginary audience. Genetic Psychology Monographs, 10, 289-305.

Markstrom, C. A., \& Mullis, R. L. (1986). Ethnic differences in the imaginary audience. Journal of Adolescent Research, 1, 289-301. doi: $10.1177 / 074355488613004$

Montgomery, M. J. (2005). Psychosocial intimacy and identity: From early adolescence to emerging adulthood. Journal of Adolescent Research, 20, 346-374. doi:10.1177/0743558404273118

O'Connor, B. P., \& Nikolic, J. (1990). Identity development and formal operations as sources of adolescent egocentrism. Journal of Youth and Adolescence, 19, 149-158. 


\section{E. P. GALANAKI}

doi:10.1007/BF01538718

Pesce, R. C., \& Harding, C. G. (1986). Imaginary audience behavior and its relationship to operational thought and social experience. Journal of Early Adolescence, 6, 83-94. doi: $10.1177 / 0272431686061008$

Petersen, A. C. (1988). Adolescent development. Annual Review of Psychology, 39, 583-607. doi:10.1146/annurev.ps.39.020188.003055

Petersen, A. C., \& Crockett, L. (1985). Pubertal timing and grade effects on adjustment. Journal of Youth and Adolescence, 14, 181-206. doi:10.1007/BF02090318

Petersen, A. C., Crockett, L., Richards, M., \& Boxer, A. (1988). A self-report measure of pubertal status. Reliability, validity, and initial norms. Journal of Youth and Adolescence, 17, 117-133. doi:10.1007/BF01537962

Peterson, C. (1982). The imaginary audience and age, cognition, and dating. Journal of Genetic Psychology, 140, 317-318.

Peterson, K. L., \& Roscoe, B. (1991). Imaginary audience behavior in older adolescent females. Adolescence, 26, 195-20.

Piaget, J. (1926). The language and thought of the child. London: Kegan Paul, Trench \& Trubner.

Piaget, J. (1929). The child's conception of the world. London: Kegan Paul, Trench \& Trubner.

Piaget, J., \& Inhelder, B. (1956). The child's conception of space. London: Routledge \& Kegan Paul.

Richter, A. L., Reaves, M. G., Deaver, H. D., \& Lacy, S. G. (1982). Social stereotypes as a variable in egocentrism. Journal of Early Adolescence, 2, 173-183. doi:10.1177/027243168200200209

Riley, T., Adams, G. R., \& Nielsen, E. (1984). Adolescent egocentrism: The association among imaginary audience behavior, cognitive development, and parental support and rejection. Journal of Youth and Adolescence, 13, 401-417. doi:10.1007/BF02088638

Ryan, R. M., \& Kuczkowski, R. (1994). The imaginary audience, self-consciousness, and public individuation in adolescence. Journal of Personality, 62, 219-238. doi:10.1111/j.1467-6494.1994.tb00292.x

Rycek, R. F., Stuhr, S. L., McDermott, J., Benker, J., \& Swartz, M. D. (1998). Adolescent egocentrism and cognitive functioning during late adolescence. Adolescence, 33, 745-749.

Schwartz, P. D., Maynard, A. M., \& Uzelac, S. M. (2008). Adolescent egocentrism: A contemporary view. Adolescence, 43, 441-448.

Shayer, M., Demetriou, A., \& Pervez, M. (1988). The structure and scaling of concrete operational thought: Three studies in four countries. Genetic, Social and General Psychology Monographs, 114, 307-376.

Silbereisen, R. K., \& Kracke, B. (1993). Variation in maturational timing and adjustment in adolescence. In S. Jackson, \& H. Rodriguez-Tomé (Eds.), Adolescence and its social worlds (pp. 67-94). Hillsdale, NJ: Lawrence Erlbaum.

Simmons, R. G., \& Blyth, D. A. (1987). Moving into adolescence: The impact of pubertal change and school context. New York: Aldine de Gruyter.

Susman, E. J., \& Dorn, L. D. (2009). Puberty: Its role in development. In R. M. Lerner, \& L. Steinberg (Eds.), Handbook of adolescent psychology. Vol. 1: Individual bases of adolescent development (pp. 116-151). Hoboken, NJ: Wiley.

Tanner, J. M. (1962). Growth at adolescence. Springfield, IL: Thomas. Vartanian, L. R. (2000). Revisiting the imaginary audience and personal fable constructs of adolescent egocentrism: A conceptual review. Adolescence, 35, 639-661.

Vartanian, L. R., \& Powlishta, K. Y. K. (1996). Demand characteristics and self-report measures of imaginary audience sensitivity: Implications for interpreting age differences in adolescent egocentrism. Journal of Genetic Psychology, 162, 187-200. doi:10.1080/00221320109597960 